\title{
APLASIA OF THE BONE MARROW : A NEW CAUSE OF THE VON JAKSCH SYNDROME
}

\author{
BY \\ G. M. H. VEENEKLAAS \\ From the University Paediatric Department Het Wilhelmina Kinderziekenhuis, Utrecht, The Netherlands
}

(RECEIVED FOR PUBLICATION SEPTEMBER 4, 1951)

Almost simultaneously von Jaksch, Hayem and Luzet described a disease characterized by anaemia with numerous immature red and white cells in the peripheral circulation and marked enlargement of the liver and spleen. The nutrition of patients with this disease had in most cases been inadequate. They often also had rickets and infections. Spontaneous recovery was the rule, but it took from one to one and a half years. Because of the many immature cells in the blood, the syndrome was called pseudoleukaemic anaemia. Nowadays this syndrome is not considered to be a separate entity and the symptoms, although to a milder degree, may be observed in anaemias and infections of various origin. Cooley's conception describes present day opinion fairly accurately: 'The terms von Jaksch anaemia and Hayem-Luzet syndrome have served their purpose and can be discarded. Nothing worthwhile has come out of that particular wastebasket-and if it accomplishes anything now, it is to encourage laxity in diagnosis.' I think I have after all been able to find something of value in this 'wastebasket .

There are children today, although they are rare, who present all the symptoms to a marked degree. Till now no satisfactory explanation for its development has been put forward. I was able to observe two patients both with severe aplasia of the bone marrow, and I am of the opinion that this may very well be the cause of the syndrome.

\section{Case Reports}

Case 1.- C.S., born on August 12, 1947, was admitted to the hospital on February 7, 1949, and discharged on August 4, 1949.

This $1 \frac{1}{2}$-year-old boy was born spontaneously, at full term, after a normal pregnancy, with a birth weight of $3,100 \mathrm{~g}$. He had been breast fed for two months and had then been fed on milk, water, flour and sugar until the age of 9 months. By that time potatoes and vegetables were added: no fruit, no cod liver oil and no vitamins $A, C$ or $D$ were given. The teeth erupted at the age of 1 year, but the child could not yet sit up alone at the time of admission. From the age of 6 months he had had an upper respiratory infection about every. month.

The parents and four other siblings were healthy. The father was a day labourer, the family living in poor circumstances.

Physical examination showed the child to be in a good nutritional condition, interested in his surroundings. The height was $71 \mathrm{~cm}$., weight $8,480 \mathrm{~g}$., temperature $37 \cdot 6$ C. There was a caput natiforme, purulent discharge from the nose, and there were two lower incisors. Many enlarged lymph nodes were palpable behind the sternocleidomastoid muscle. A rachitic rosary and Harrison's grooves were present. The liver was palpable two fingerbreadths below the costal margin: the spleen almost reached the iliac crest. Epiphyseal swellings of the extremities were present. Otherwise nothing abnormal was found. Urine and faeces were normal. Serological reactions for syphilis and cutaneous tests for tuberculosis were negative. The galactose tolerance test was normal. There were no signs of haemolysis, no urobilinuria or bilirubinaemia. There was no $\mathrm{Rh}$ or $\mathrm{ABO}$ antagonism between the parents.

BloOD Examination. This gave haemoglobin $60^{\circ}$, erythrocytes $3 \cdot 36$ million per c.mm.. slight anisocytosis, poikilocytosis, polychromasia. The Price-Jones curve was within normal limits. Reticulocytes were $6^{\circ}$, thrombocytes 142,280 per c.mm., leucocytes 19,200 per c.mm. (myelocytes 5, metamyelocytes 4 , band forms 15 , polymorphonuclear neutrophils 36 , monocytes 5 , lymphocytes 35 , erythroblasts 30 ). The blood sedimentation rate was $20 \mathrm{~mm}$., the coagulation time was 2 minutes 45 seconds, the bleeding time 3 minutes 45 seconds. The blood phosphorus was $2 \mathrm{mg}$. per $100 \mathrm{ml}$., calcium $8.2 \mathrm{mg}$. per $100 \mathrm{ml}$., phosphatase 136 units, ascorbic acid $0.2 \mathrm{mg}$. per $100 \mathrm{ml}$.

Bone Marrow Examination. In the bone marrow smear numerous reticular cells were seen, whereas the bone marrow elements, such as myelocytes and erythroblasts (Fig. 1) were scarce. (These cells were fairly 
numerous in the peripheral circulation.) Bone marrow punctures were performed in the sternum, the ilium and the malleoli. Microscopic examination of a tibial bone marrow sample showed a picture similar to that of the smear, i.e. scarcity of bone marrow elements. Reticular elements were visible, but almost no myelocytes and no erythroblasts. As far as they were seen, they were mostly situated in the outlying part of the bone marrow bordering on the cartilage (Figs. 2 and 3).

TreatMent. The patient was put on a diet rich in vegetables, fruit and proteins, while $300 \mathrm{mg}$. ferrous lactate, $50 \mathrm{mg}$. ascorbic acid, 1,000 I.U. vitamin D and 3,600 I.U. vitamin A were given daily. When it appeared that the red blood picture did not react to treatment injections of liver extract were given, followed by folic acid. $15 \mathrm{mg}$. daily. Ultra-violet irradiation was instituted twice weekly from the 64th day of the child's stay in hospital or he was placed outdoors when the weather permitted; 126 days after admission the adenoids were removed.

ColRSE. The general condition improved very slowly and gradually during the six month's stay in hospital. Nose and throat infections occurred a few times. His rickets were cured rapidly. Towards the end of his stay the child could stand and had six teeth. He weighed $9,630 \mathrm{~g}$. Phosphorus and phosphatase values were normal. On June 29, 1949, the calcium was $9.4 \mathrm{mg}$. per $100 \mathrm{ml}$., phosphorus $6 \mathrm{mg}$. per $100 \mathrm{ml}$. and phosphatase 18 units. The liver and spleen had gradually become smaller, and were only just palpable at the time of discharge. The values for haemoglobin and red cells, however, remained practically constant (Fig. 4). There was a slight reticulocyte crisis 30 days after admission. but after another month the number had returned to normal. After six weeks a few erythroblasts were found in the peripheral blood: after seven weeks the white blood picture had become normal: leucocytes 7,900 (eosinophils 2, polymorphonuclear neutrophils 28 , lymphocytes 65 , monocytes 5 ).

Three months after admission a slight increase of the myelocytes and erythroblasts in the bone marrow was noted, and remained practically unchanged until the end of the hospital stay. Microscopic examination of a biopsy specimen of tibial bone marrow obtained a few days before discharge revealed a slight increase of the specific cells of the marrow, but it was still characterized by a preponderance of reticular cells and scarcity of myelocytes and erythroblasts.

On December 21, 1950, the child was re-examined and found to be in excellent condition. He was now 3 years old; height was $94 \mathrm{~cm}$., weight $15 \mathrm{~kg}$. The liver and spleen could not be palpated. Blood values were as follows: Hb. $74^{\circ}$, red cells $4.68 \mathrm{~m}$. per c.mm., reticulocytes $0 \cdot 2^{\circ}$, leucocytes 11,100 per c.mm. (eosinophils 2, polymorphonuclear neutrophils 33, lymphocytes 62. thrombocytes 272,080 per c.mm.). Bleeding time was 1 minute 30 seconds and coagulation time 2 minutes 30 seconds. The bone marrow had numerous cells and did not differ from normal bone marrow of that age.

Case 2.-I had occasion to see a second case showing the same clinical syndrome which, to save space, is not described fully. Treatment in this case consisted of giving a complete diet. In the course of a few months the symptoms disappeared. When this patient was first seen the bone marrow was atrophic and contained chiefly reticular cells. In the smear this preponderance was quite remarkable (Fig. 5). A biopsy specimen showed that red and white cells were still being formed on the border line of cartilage and bone, but elsewhere the marrow spaces were empty, except for reticular cells (Fig. 6). Four months after the beginning of treatment the blood picture had become normal and the liver and spleen were still palpable. A year after treatment these organs were no longer palpable and the bone marrow had become normal (Fig. 7).

Other Cases.-Bone marrow smears of a patient who had been in hospital 16 years previously with the same history and identical symptomatology were also characterized by a scarcity of plastic elements and abundance of reticular cells. At that time we were unable to diagnose this picture and ascribed these findings to poor technique. In this patient, and in six others seen in the course of the intervening years presenting identical symptoms and recovering in a few months under a complete diet, we did a new bone marrow biopsy. In all these patients the bone marrow was normal.

\section{Discussion}

Clinically these two patients presented the typical picture of von Jaksch pseudoleukaemia. The previous history revealed deficient nutrition and recurrent infections. They both had rickets. Besides hepatosplenomegaly numerous immature red and white cells were found in the blood. In the first patient a rapid reaction to treatment with iron, liver extract or folic acid was neither expected nor seen, but there was a slow, steady improvement, as is also seen when infections become less frequent and when an adequate diet is given, as was observed in the second patient.

An entirely new aspect of the syndrome is the lesion of the bone marrow. It is difficult to determine what really causes the bone marrow aplasia. Infections, deficient nutrition and rickets, separately or together, do not always lead to the development of the von Jaksch syndrome. It is not known whether or not the bone marrow is involved in these cases, and considering the rarity of the simultaneous occurrence of malnutrition, infections and rickets in a country where infant welfare is well organized, it is hard to establish this definitely. A connexion between this bone marrow aplasia and the von Jaksch syndrome is highly probable. The coincidence of only slight improvement of the bone marrow aplasia with a disappearance of the syndrome may lead to the conclusion that this syndrome only develops fully when there is a marked aplasia of the bone marrow and is therefore rarely seen. 


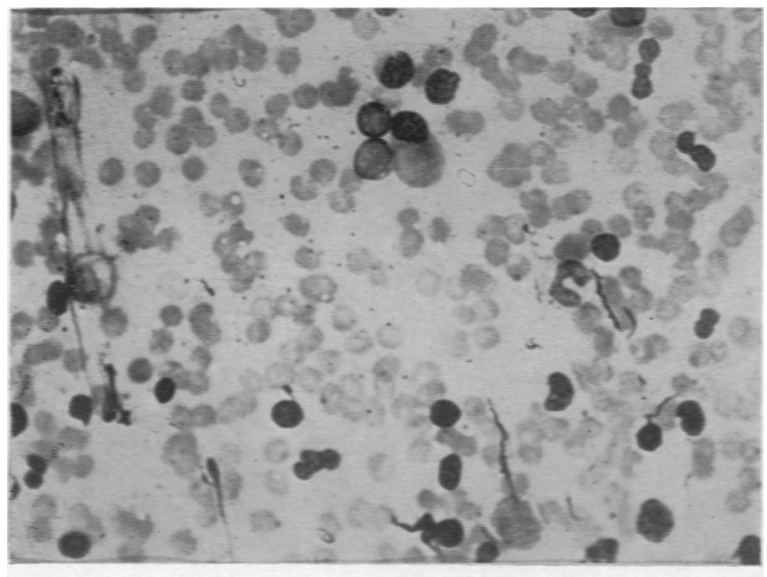

Fig. 1.

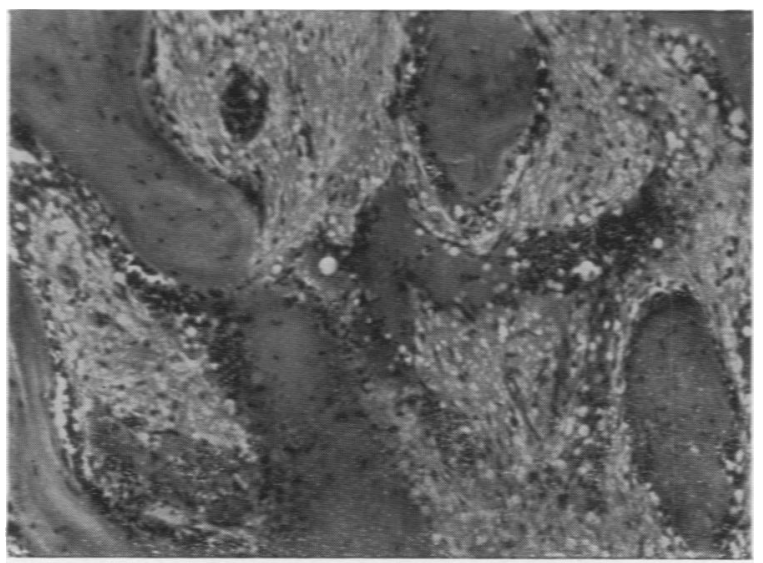

FIG. 2.

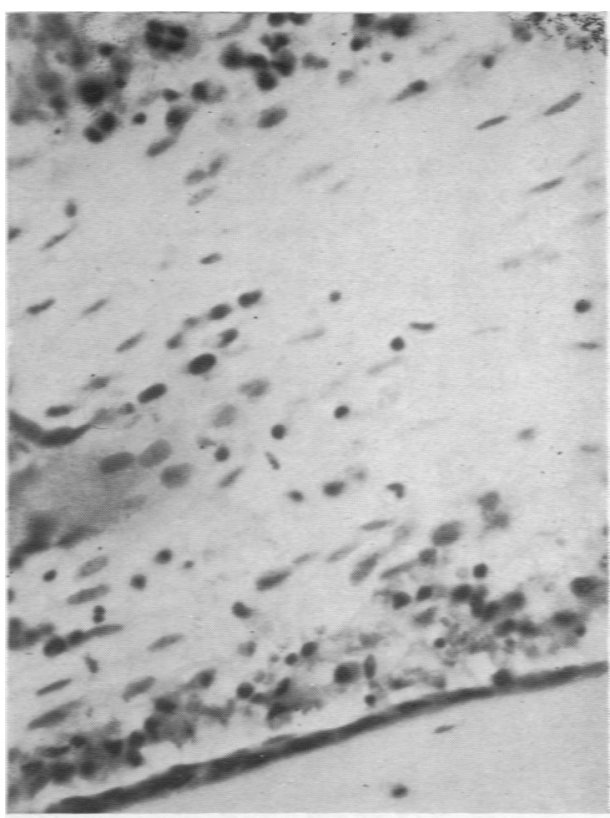

FIG, 3.

Fig. 1.-Case 1. Bone marrow smear showing numerous reticulum celk, very few erythroblasts or myelocytes.

Fig. 2-Case 1. Section of tibia marrow showing marked aplasia.

Fig. 3.-Case 1. Section of tibia marrow showing aplasia and myelocytes and erythroblasts only at the edges near the bone.
Fig. 4-Case 1. Constant levels of erythrocyte and haemoglobin values regardless of various treatments.

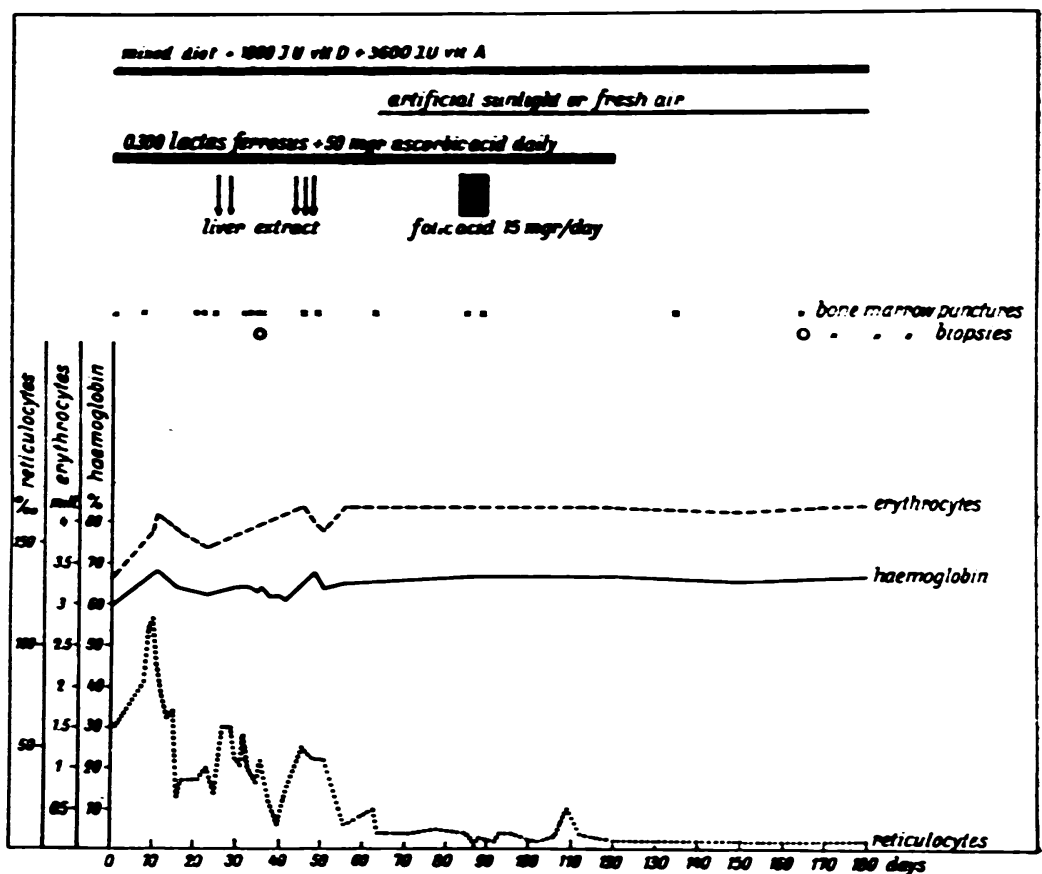

Fig. 4. 
A lesser degree of aplasia might occur without or with only slight enlargement of the liver and spleen. Once my attention was drawn to this fact, I saw several cases with slight aplasia of the bone marrow, especially in cases of anaemia. In these cases the anaemia was of many months standing and was microcytic and hypochromic. There were no changes in the white cells, but erythroblasts were regularly seen in the peripheral circulation. The bone marrow was normal so far as the white cells were concerned, but there were more reticular cells than normally seen, while at the same time the red system presented a scarcity of elements.

Rohr (1949) advanced the hypothesis that immature cells always have their origin in extramedullary foci. It is not known whether this holds true for all cases and for all degrees in which the phenomenon occurs. Important arguments in favour are the following. From present day knowledge it is assumed that the bone marrow circulation is a closed system whereas the spleen has an open system. The liver haemopoiesis is partly intravascular. During foetal life, when spleen and liver participate in haemopoiesis, immature elements in the peripheral circulation are numerous. In leukaemia with considerable enlargement of the spleen and liver the number of cells in the blood is high, and irradiation of the spleen causes a rapid decrease of cells. In aleukaemic forms marked spleen and liver enlargement are absent. This theory tends to explain the 'hiatus leukaemicus'. We did not perform either liver or spleen biopsy in our very youthful patients, which might have furnished data on the presence of haemopoietic foci in these organs. The scarcity of immature cells in the bone marrow and their abundance in the blood make it seem probable that these cells originated in extramedullary foci, and in cases with marked hepatosplenomegaly it seems likely that these are the site of origin, the more so as disappearance of the immature cells from the peripheral circulation is found simultaneously with a decrease in size of these organs. Extensive haemopoiesis in the liver and spleen were found at necropsy of these patients. Since the disappearance of immature cells from the circulation and a decrease of hepatosplenomegaly

Fig. 5.-Case 2. Bone marrow smear showing prevalence of reticulum cells, scarcity of myelocytes and erythroblasts.

Fig. 6.-Case 2. Section of tibia marrow showing central aplasia and erythroblasts and myelocytes in the periphery.

Fig. 7.-Case 2. Section of tibia marrow one year later. A state of normal activity has returned.
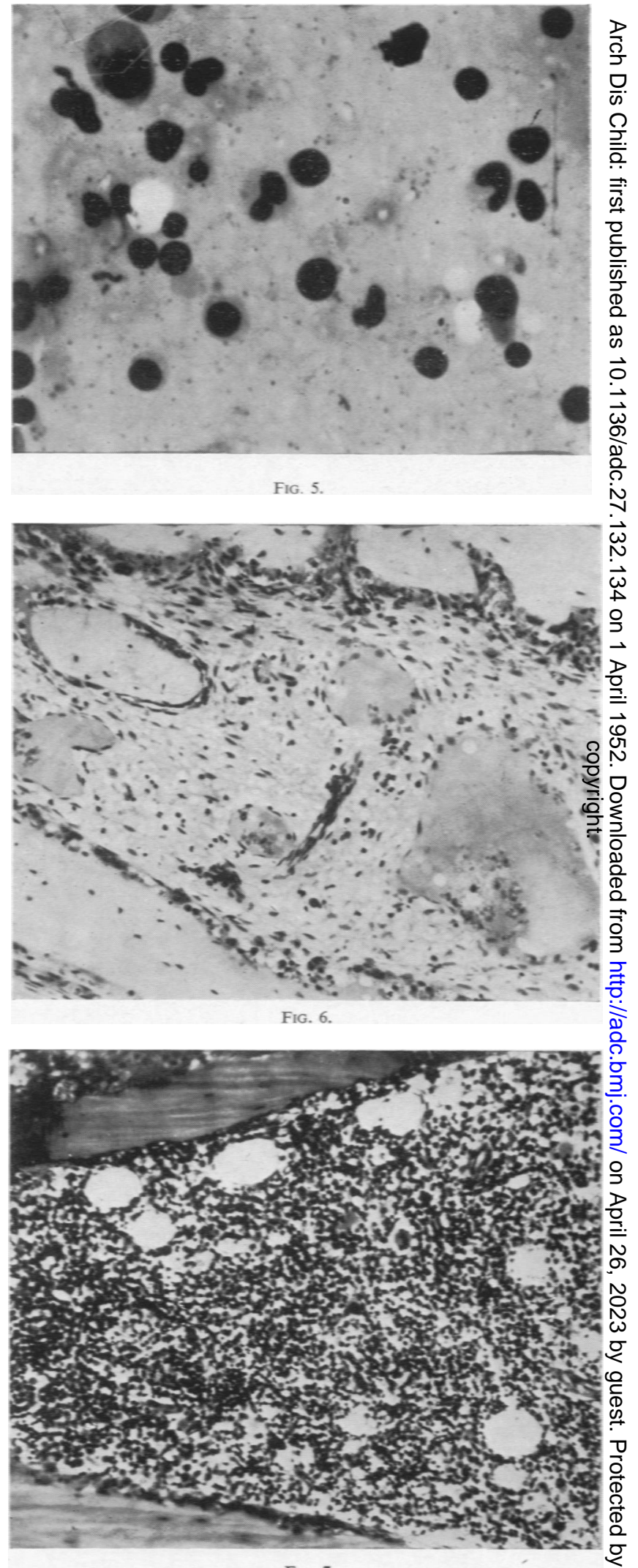

FIG. 7 
coincide with improvement in the atrophied bone marrow a connexion between the three symptoms is self-evident. Considering the large reserves possessed by the bone marrow, a slight improvement of the haemopoietic function may make extramedullary haemopoiesis superfluous.

During various infections in young children a few immature cells are found in the blood stream, and haemopoietic foci may be encountered in the liver and spleen without any impairment of the haemopoietic function of the bone marrow.

It is well known that the action of different infectious or toxic noxae on the bone marrow may be followed by a decrease in the number of one or more cell types. It seems, therefore, highly probable that in cases such as those described above, the lesion of the bone marrow being severe and needing a long time for its repair, cell production is taken over by the liver and spleen, which possess this capacity to a heightened degree at this early age.

The sequence of events might be as follows: recurrent infections and deficient nutrition; reaction of the bone marrow with a scarcity of plastic elements; in case of failure of the bone marrow to recuperate quickly enough, vicarious functioning of the liver and spleen; with discontinuance of recurrent infections and deficient nutrition the haemopoietic function of the liver and spleen is gradually taken over by the bone marrow.

In our patients the anaemia was microcytic and hypochromic. In the literature a colour index above 1 is sometimes mentioned. This is not surprising, as the anamnesis of the von Jaksch syndrome reveals deficient nutrition, and the type of this deficiency determines whether the subsequent anaemia will be macrocytic or microcytic, hyperchromic or hypochromic. The syndrome is rarely seen nowadays as compared with a few decades ago, because in general nutrition has markedly improved.

\section{Summary}

Two patients with a well defined von Jaksch syndrome presented hepatosplenomegaly, anaemia and numerous immature red and white cells in the blood stream, with severe aplasia of the bone marrow.

In smears, as well as in biopsy material of the bone marrow, reticular cells were found almost exclusively.

Both patients had had a deficient diet and numerous infections and both had rickets. With a normal diet the immature cells disappeared from the blood, the liver and spleen returned to normal size in the course of some months, while at the same time the aplasia of the bone marrow improved. A normal bone marrow was found in both patients one and three-quarter years and one year respectively after treatment.

Based on these observations we regard it as possible and even probable that the von Jaksch syndrome arises as a sequence of, and is therefore secondary to, aplasia of the bone marrow.

\section{REFERENCES}

Cooley, T. B. (1949). Brennemann's Practice of Pediatrics.' Vol. 3, ch. 16, p. 30. Hagerstown, Maryland.

Rohr, K. (1949). 'Das menschliche Knochenmark.' Stuttgart. 